\title{
The role of HRM in generating Innovation \& Creativity - helping or hindering??
}

Our second issue for 2019 carries on the theme of creativity and innovation from Issue 1 to examine specifically focus on the HRM domain. Creativity and the ability to innovate are acknowledged as crucial features of business sustainability and success but these skills lie in their human resources. The challenge for the organization is one of how to leverage individual and team ability to generate ideas that are both useful and new and can be implemented to solve a novel and significant problem. This also sees the need to manage a process where the role of individuals are front and centre as the source of new ideas, the ones who develop ideas, and also as the ones who have responsibility to propose and champion and them to implement the ideas. The common view is that likelihood of innovation can be enhanced by management practices, and Human Resource Management (HRM), in particular has a crucial function in managing the innovation processes (see for example Amabile, 1997; Collins, 1999; Li, Zhao \& Liu 2006). For many organizations, their HRM practices are crucial to influencing and shaping the attitudes, behaviour and actions of their staff in delivering the creativity and innovation they need to survive and thrive.

The dual role of HRM noted by Boxall \& Purcell (2011) provides an important framing for the 9 papers presented in this issue. On the one hand some of the papers deal with the more macro view of HRM policies and practices for organizing and managing work, while the second perspective is the micro view of individual management activities such as recruiting, motivating, developing and retaining employees through to the processes to inform, consult and negotiate with individuals and groups. Providing this dual role of HRM allows this issue to provide perspectives that range from the broad question as to the strategic value of HRM through to an examination of the policy and practices HRM purportedly supports.

Our first paper begins with a macro view as to the alignment between HRM and line managers as to the value of HRM. It is a real life question that takes the academic theory out of the classroom and text book and, as Navío-Marco, Solórzano-García and Palencia-González reveal in their paper (aptly titled HR management as key pillar of company strategy: Analysis of the line managers' perception), it is not one where HRM emerges as well as many of us may have hoped ...but the authors do suggest that there is hope so have a read and see what you think.

In our second offering, authors Jerez-Gómez, Céspedes-Lorente and Pérez-Valls explore the relationship between high-performance human resource practices and organizational outcomes with organizational learning capability as a mediating variable. They also offer hope in aligning HRM activities with organizational outcomes in their conclusions around elements such as the design suitable conditions for promoting organizational learning capability.

Our third paper provides a very different but just as important macro view of the way HRM practices and policies operate. In their paper titled 'Collectivism-oriented HRM and individual creative contribution: The roles of value congruence and task interdependence' authors Chen, Zhang, Jiang, Shi and Liu examine whether collectivism-oriented human resource management (HRM) system influences the creative contribution individuals make in research teams. Again, their findings offer insight into how organizations could develop theirs HRM system and improve individual creative contribution in research teams. 
In 'Human Resources Practices as Predictors of Organisational Citizenship Behaviour: the role of job breadth and organizational support' we find authors Pohl, Vonthron and Closon diving deep into an examination of the mediating and moderating processes through which satisfaction with developmental human resources practices are so often assumed to be linked to organizational citizenship behaviour. Those interested in the moderation/ mediation tension will enjoy the journey this paper takes us on to find out what this really looks like and means in an organizational setting.

Collaboration was a strong feature in the papers in our first issue of 2019 and it emerges again in fifth paper here where Anzola-Román, CBayona-Sáez and García-Marco seek to answer the question as to which organizational factors help to overcome the challenges that firms face in the different phases of the collaborative innovation process? Drawing on both the literature as well as three case studies, the authors present us with a theoretical framework which they suggest identifies the organizational context factors that determine the success or failure of collaborative innovation practices.

The paper also serves as a nice entre into the next one by Cole, Cox and Stavros who take us into to the individual perspective in their examination of the effect of emotional intelligence on team collaboration. As the authors themselves say, this "research has important implications for teams and their pervasive use in business" today.

Paper 7 by Silva and Coelho takes up the emotional intelligence concept in a different way to investigate its influence on creativity. While they fully acknowledge issues with generalizability, this paper will delight many in both the wider management discipline as well the more focused area of HRM as it presents new and practical ideas for training programs, particularly the need for soft skills.

This practical nature and implications of academic research are very much to the fore in the paper by Vazquez-Bustelo and Avella - and this is nicely summed up in their title of The Effectiveness of High-Involvement Work Practices in manufacturing firms: Does Context Matter?'. By adopting an integrative approach to the universal and contingency frameworks for analyzing the effectiveness of high-involvement work practices (HIWPs), the authors' are able to offer a broader view about the potential success of contemporary human resources practices.

Our last paper completes the theory meets practice perspective by returning to a wider view of HRM with a paper by De Paoli Sauer and Ropo which examines office design as a spatial context of organizations designed "to support employee creativity, foster company innovation and communicate a positive company image". It is a delightfully critical paper that identifies three dominant contradictions in the existing literature on creativity and workspaces. It makes a fitting ending to an issue which seeks to cover the breadth and depth of both the promise and real deliverables in the management of workplace creativity and innovation. Overall, HRM is shown to have much to offer but also needs to be aware that processes and policies can hinder as much as they can help.

\section{Associate Professor Tui McKeown Editor in Chief, JMO Tui.mckeown@monash.edu}

\section{References}

Amabile, T. (1998). How to kill creativity. Harvard business review.

Boxall, P., \& Purcell, J. (2011). Strategy and Human Resource Management. London: Palgrave Macmillan.

Collins, M. A., \& Amabile, T. (1999). Motivation and creativity. In R. J. Sternberg (Ed.), Handbook of creativity. Cambridge: Cambridge University Press.

Jiang, J., Wang, S., \& Zhao, S. (2012). Does HRM facilitate employee creativity and organizational innovation? A study of Chinese firms. The International Journal of Human Resource Management, 4025-4047. 